O PAPEL DO JUDICIÁRIO NA DEMOCRACIA ATUAL

\title{
THE ROLE OF THE JUDICIARY IN DEMOCRACY
}

Tercio Sampaio Ferraz Junior ${ }^{1}$

\section{RESUMO:}

O ensaio retoma e discute as diversas acepções do termo democracia, analisa o conceito de "interpretância" e reflete sobre a neutralidade política do poder judiciário. A introdução de exigências externas transforma o modo de encarar a Constituição, implicando num deslizamento do Poder Constituinte para o Poder Constituído. A conclusão é que a democracia parece buscar sua legitimação não mais por meio da constituição política e seus guardiões, mas através dos potenciais meios comunicativos que se agrupam em torno dos novos e diferentes meios de comunicação da sociedade.

Palavras-Chave: Poder judiciário, política, democracia, neutralidade.

\begin{abstract}
:
The essay takes up and discusses the different meanings of the term democracy, analyzes the concept of "interpretance" and reflects on the political neutrality of the judiciary. The introduction of external requirements transforms the way of looking at the Constitution, implying a shift from the Constituent Power to the Constituent Power. The conclusion is that democracy seems to seek its legitimacy no longer through the political constitution and its guardians, but through the potential communicative means that are grouped around society's different means of communication.
\end{abstract}

Keywords: Judiciary, politics, democracy, neutrality.

\footnotetext{
${ }^{1}$ Possui graduação em Filosofia, Letras e Ciências Humanas pela Universidade de São Paulo (1964), graduação em Ciências Jurídicas e Sociais pela Universidade de São Paulo (1964), doutorado em Filosofia pela Johannes Gutemberg Universität de Mainz (1968) e doutorado em Direito pela Universidade de São Paulo (1970). Atualmente é consultor da Coordenação de Aperfeiçoamento de Pessoal de Nível Superior, professor titular da Pontifícia Universidade Católica de São Paulo, professor aposentado da Universidade de São Paulo e professor emérito pela Faculdade de Direito da USP - Ribeirão Preto. Tem experiência na área de Direito, atuando principalmente nos seguintes temas: direito, democracia, poder, constituição e ordem econômica. Lattes:http://lattes.cnpq.br/0037990716909329. ORCID: https://orcid.org/0000-0002-4373-3138. E-mail: tercio@sampaioferraz.com.br
} 


\section{O PAPEL DO JUDICIÁRIO NA DEMOCRACIA ATUAL}

Democracia é um dos lugares-comuns mais importantes da retórica política de nossa era. Em seus traços elementares, o ideal democrático, configurado desde os pensadores iluministas do século XVIII, mostra um processo de como lidar com relações de inclusão e exclusão, sejam pessoas ou grupos, classes, sexos, raças, países, regiões.

Democracia, nesse sentido, contém em seu étimo a noção de povo, demos, populus, plebs. Um pouco herança da Revolução Francesa, costuma-se presumir o povo constituído na nação como uma unidade indissolúvel, donde a vinculação dos que exercem o poder com o todo da nação e não com os indivíduos nela agrupados.

A expressão, contudo, não tem nem tinha, à época, uma estabilidade semântica. O que levou Jaucourt na Encyclopaedie a assim manifestar-se "povo (peuple), nome coletivo de difícil definição, pois nele se tem ideias diferente em diversos lugares, em variados tempos, conforme a natureza dos governos".

Em 1789 a ambiguidade apareceu, e a Declaração de 26 de agosto foi assinada (conforme proposta de Mirabeau), "pelos representantes do povo francês", embora em seu art. $3^{\circ}$ estivesse dito: "O princípio da soberania reside essencialmente na Nação".

À moda da Revolução Americana, o povo enquanto povo real, já se supunha constituído de seus cidadãos ativos, que agem em grupos. Em 1787, Charles Pickney diria: o povo norte-americano divide-se em três classes, os profissionais liberais, os comerciantes e os proprietários rurais e, "embora distintas quanto às suas atividades, são individualmente iguais na escala política, podendo ser facilmente provado que elas têm um só interesse".

Por conta dessa imprecisão semântica e pragmática, pode-se entender que, em seus traços elementares, o ideal democrático, configurado desde os pensadores iluministas do século XVIII, mostre um processo de como lidar com relações de inclusão e exclusão, inclusão dos antes excluídos, sejam pessoas ou grupos, classes, sexos, raças, países, regiões, inclusão esta que gerava, porém, novas exclusões e pedia novas inclusões. Por exemplo: o mencionado Charles Pickney, representante da Carolina do Sul, quando da criação do Senado, não incluiu os escravos. Robespierre, com os Jacobinos, exigiu que se voltasse a falar de soberania do povo, em forte alusão à plebe e com exclusão dos nobres, clérigos e burgueses.

Isso gerou disputas em torno do sentido unívoco da soberania popular (sede do consenso) e do modo como lidar-se com as relações entre maiorias e minorias.

Em seus traços elementares, o ideal democrático, configurado desde o século XVIII, vinha, assim, sustentado sobre dois pilares: a ideia de representação dos governados pelos governantes e 
a ideia de identidade ou comunhão entre ambos. Representação significou, no correr dos anos, participação mediatizada e institucionalizada através dos instrumentos políticos conhecidos, como eleições, mandatos populares, pluralismo partidário, liberdade de expressão etc. Identidade ou comunhão quis dizer identificação de uma coletividade em termos de participação simbólica, comunidade autêntica de crenças e estilos de vida, politização tanto de governantes quanto de governados em torno de bases e objetivos, enfim, sentimento de agregação com base em símbolos comuns, capazes de expressar uma vontade comum, a unir indistintamente governantes e governados. Donde o sucesso da expressão nação.

Kelsen (2018 [1920]) percebe nesse entrelaçamento a questão básica da definição do princípio democrático. "Democracia", diz ele, "significa identidade de governante e governado, de sujeito e objeto do domínio, significa domínio do povo sobre o povo". Assim, se a representatividade lida com as diferenças, relações majoritárias/minoritárias, a comunhão ou identidade envolve, antes, o tema do consenso.

Embora os dois pilares fossem entendidos como constituindo um conjunto solidário, a chamada democracia representativa, na prática, se impunha um jogo difícil.

Implicava, afinal, uma dificuldade em expressar um razoável equilíbrio, entre lograr fazer prevalecer interesses transcendentes aos interesses dos indivíduos, submetê-los a regras objetivas do jogo social e resguardar os interesses particulares de cada um.

Bobbio sintetiza com felicidade esse jogo: "por regime democrático, entende-se primariamente que exista um conjunto de regras de procedimento para a formação de decisões coletivas, no qual se prevê e se facilita a maior participação possível dos interessados". Donde uma de suas regras fundamentais: "nenhuma decisão majoritária pode limitar direitos das minorias, especialmente o direito a tornar-se maioria em igualdade de condições (...)" (BOBBIO, 1981).

Por óbvio, essas regras do jogo não sustentariam, por si sós, uma democracia. Isso implicaria, desde o Século XIX, definir uma ordem como democrática mediante a afirmação de que todas as normas e todas as decisões dotadas de império pertencem ao espaço da lei - vontade majoritária - à exclusão de qualquer outro quando pretenda sobrepor-se a ele, mas também fazendo a produção normativa remontar, em última análise, a uma fonte hegemônica do consenso de todos.

Dito de outro modo, num mundo socialmente complexo, caracterizado pelas crescentes multiplicidades qualitativas e pluralidades quantitativas, em um regime democrático, antes de tudo, ter-se-ia de ser capaz de lidar com a necessidade e a escassez de consenso.

A Declaração dos Direitos do Homem e do Cidadão de $1789^{2}$ bem manifesta essa dificuldade. Nela, a conservação dos "direitos naturais e imprescritíveis do homem” é considerada

\footnotetext{
2 http://www.direitoshumanos.usp.br Consulta em 27/08/2021.
} 
o "fim de toda associação política" $\left(\mathrm{n}^{\mathrm{o}} 2\right)$. A liberdade, enquanto "poder de fazer tudo quanto não prejudique a outrem" $\left(\mathrm{n}^{\circ} 4\right)$ permitirá entender assim a "utilidade comum” e, simultaneamente, as “distinções sociais" $\left(\mathrm{n}^{\mathrm{o}} 1\right)$. Os direitos humanos constituíam assim um princípio de unidade e integração num mundo de diversidade e atomização.

Um modelo politicamente democrático implicaria, assim, uma forma de lidar com os diferentes círculos sociais (o templo, o palácio, a casa, a rua, a aldeia, o campo), marcados por suas relações diferenciais, assegurando a eles, simultaneamente, sua expansão diferenciada e sua significância unitária.

Donde governar democraticamente uma sociedade implicaria mecanismos capazes de estabelecer uma coexistência legítima entre a necessidade de tomar decisões em nome da coletividade e as inevitáveis decepções que ela provoca.

Em outras palavras, a força da democracia estaria nessa peculiar atitude perante o consenso, no sentido de que, num regime democrático, a representatividade se torna autêntica não pelo resultado, mas antes pela garantia consensual de manifestação do dissenso.

Nesses termos uma democracia se mostra como um regime que se legitima porque torna possível conviver com a mudança contraditória das estruturas: pela vontade representativa dos parlamentos, o que vale hoje, pode deixar de valer amanhã e pode voltar a valer depois, mas sem que a variabilidade perturbe a impositividade imperativa da ordem. Pois a ordem não exclui, porém não depende nem de políticas circunstanciais de acordos partidários, nem do saber e do sentir governamental, mas de uma unidade que os mantém íntegros na sua diversidade. Daí a função da tripartição de poderes. Mediante ela, o poder se divide e se controla, check and balance.

Sua força, porém, não estaria apenas em sua capacidade de manter as distinções entre os círculos e suas ramificações numa atmosfera de um continuum: o privado e o público, o incidente familiar e a ordem social, a desordem social e a ordem política, a desordem política e a ordem econômica, a desordem econômica e a ordem financeira. Ao mesmo tempo seria preciso permitir o salto de um círculo para o outro, para que novos círculos brotem e os antigos sejam realimentados, de modo a vencer a entropia própria do sistema.

Para isso uma democracia não podia se resumir apenas nessa tarefa de organizar em círculos distintos e concêntricos o poder político: um legisla, outro executa, outro julga. Era preciso conter o regime trágico da dúvida infinita: a sentença remete ao regulamento, o regulamento remete à lei, a lei remete à constituição, a constituição remete a si mesma. Nesse processo redundante, a constituição buscaria sua legitimação derradeira na política democrática (uma constituinte eleita: soberania popular) e, inversamente, a política buscaria a legitimação na soberania na constituição (a constituição como um conjunto de normas, emanadas de uma decisão política do povo). 
Mas para que essa fundamentação recíproca funcionasse, ao eixo político que liga a legislação à execução e remete ao julgamento, se acrescentou um eixo paradigmático, o eixo da interpretação, uma espécie de mecanismo secundário a serviço do regime de check and balance.

\section{INTERPRETÂNCIA}

Para isso foi preciso um mecanismo secundário a serviço da tripartição com seu regime de check and balance.

Trata-se do mecanismo da interpretância: como a interpretação é um continuum redundante, afinal é inútil pretender ultrapassar a interpretação, pois ela se estende ao infinito sem que nada se encontre para interpretar que não seja uma outra interpretação, seria preciso submeter a interpretação a um ponto em que ela não restituísse um novo significante e uma nova interpretação: a melhor, a mais pesada, a mais radical, uma espécie de silêncio significativo.

Ou, em termos da legislação, ao seu sentido último e indiscutível, que se revela paradoxalmente na sombra de uma negação: isto, aquilo não é lei. Ao eixo político que liga a legislação à execução e remete o decreto à lei, se acrescenta um eixo paradigmático, o eixo da interpretação, no qual a lei talha para si um significado conforme, um significado que não cessa de fornecer outro significado, uma espécie de significante que se recarrega e se reproduz continuamente.

Entende-se, assim, que para a estrutura democrática funcionar exigiu-se a configuração de uma instância interpretativa última. Nesse modelo, sua estabilidade decorria igualmente, de uma premissa limitativa funcionalmente imprescindível: um poder interpretativo, instancialmente último, cujo arbítrio seria controlado por uma regra de autocontenção: suas decisões seriam programadas e não programantes, a regra do legislador negativo. Como se percebe na distinção entre poder constituinte e poder constituído (SIÈYES, [1789]) ou na noção de Paramount law dos revolucionários americanos.

É inegável que esse modelo, sob o aspecto histórico, tornou-se um êxito tão retumbante que, não obstante eventuais dificuldades, até fins do século XX, a democracia dita constitucional se estendeu também de modo generalizado, em todos os campos do Estado de Direito. Não só na constituição de Estado, nas garantias processuais do Estado de Direito, na divisão de tarefas entre o Legislativo, o Executivo e o Judiciário, a produção do direito foi coerentemente atribuída à política: democracia parlamentar. Sob o aspecto técnico-jurídico, isso se tornou possível através de ficções em certa medida plausíveis: através da ampla hierarquia normativa estatal, que recepcionou inclusive normas contratuais e normas internas de associações, através da delegação do poder de criação do direito a particulares e através da recepção e do controle pelo Estado de normas sociais. 
Entende-se, assim, que para a estrutura democrática exigiu-se a configuração de um Poder de Estado politicamente neutro e para sua neutralização, uma instância última, sui generis, que tudo controla mediante um poder supremo de veto: o supremo poder normativo deve ser politicamente castrado; é o legislador negativo.

\section{O PAPEL DO PODER JUDICIÁRIO}

Concebido desse modo, o Poder Judiciário se constituiu na pedra angular da legitimidade dos regimes democráticos, pois, só mediante ele os efeitos da imposição normativa podem conciliar o atendimento parcial de necessidades imediatas (função expressiva da execução da lei), e satisfazer também finalidades distantes, não imediatas, como a realização da justiça, do bem-estar e da paz social (função instrumental da legislação) ${ }^{3}$. O Poder Judiciário torna possível a congruência entre as duas funções (expressiva e instrumental).

Contudo, para exercer essa função era preciso que esse Poder fosse politicamente neutro. Vale dizer, a chave da legitimidade democrática, a pedra angular da legitimidade democrática, é peculiarmente garantida pelo papel da judicatura, configurado mediante regras neutralizadoras de sua atividade (imparcialidade, independência, mandato permanente) e organizado na forma de uma hierarquia instancial.

A neutralização política do Judiciário não é, propriamente, um tipo de indiferença genérica, uma espécie de alheamento político. Neutralizar, portanto, não significava tornar genericamente indiferente, mas gerar uma indiferença controlada, ou seja, estabelecer uma relação de indiferença, garantida contra expectativa de influência. A neutralização, nesse sentido, não torna o Judiciário imune, de fato, a pressões de ordem política. Sua neutralização não se dá em face dos fatos, mas das expectativas institucionalizadas: ainda que de fato haja pressões políticas, estas institucionalmente não_contam. A independência do juiz exige que a crença nela esteja enraizada profundamente na população. Pois só desse modo a pressão política, como fato, se descarta como versão ética.

E esse o papel do Poder Judiciário na democracia tradicionalmente concebida. O que mudou?

Essa estrutura e esse papel estrutural do Poder Judiciário funcionou razoavelmente até meados do Século XX, quando começou a perder a operacionalidade.

$\mathrm{O}$ advento da sociedade tecnologicamente massificada (internet, redes sociais) parece, com isso, desenvolver novas exigências, a começar por uma desneutralização política do próprio juiz,

\footnotetext{
${ }^{3}$ Sobre essas funções ver Luhmann,1983, p. 315 ss.
} 
que é chamado, então, a exercer uma função sócioterapêutica, liberando-se do apertado condicionamento da estrita legalidade e da responsabilidade exclusivamente retrospectiva que ela impõe (julgar fatos, julgar o passado em nome da lei dada), obrigando-se a uma responsabilidade prospectiva, preocupada com a consecução de finalidades políticas (julgar no sentido de prover o futuro).

Surge, então, do ângulo interno, uma espécie de desorientação na dogmática jurídica que culmina no chamado consequencialismo a justificar o chamado ativismo judicial mediante instrumentos jurídicos (donde a retomada do direito natural na aceitação da incidência direta de princípios), que, porém, expõe o paradoxo político: como explicar o sentido democrático de decisões programantes, tomadas por juízes que não são eleitos por voto popular?

Do ângulo externo, observa-se, então, entre a proclamação formal dos direitos e o real estatuto político dos indivíduos e dos grupos, com suas diferenças, a extensão de um vasto espaço ocupado por formas antigas e novas de tensão social que parecem colocar-se na forma de desafios inteiramente novos.

Questões de ordem política continuam abertas à decisão política. A ideia de imposição de limites ao exercício político continua um conceito básico. Mas a vinculação do privado ao público em termos de um Estado - democrático - de Direito parece sofrer uma espécie de erosão.

Como se fossem subvertidos os conceitos tradicionais de consenso e representação, mediante uma explosão incontrolável de manifestações de dissenso. O que, certamente, traz consequências importantes para o Estado democrático de Direito e para o papel legitimador do Poder Judiciário.

Com isso renuncia-se à ideia tradicional de que a constituição política daria à energia coletiva de uma sociedade nacional a forma como ela se constitui como nação. Pelo contrário, a sociedade da modernidade acaba caracterizada justamente pelo fato de o potencial coletivo não estar mais disponível como unidade. E quando o próprio direito coloca subsetores sociais (mídia, redes sociais, blogs) no lugar da política, a qualidade legitimadora do Poder Judiciário necessariamente também se modifica. Então, a democracia parece buscar sua legitimação, em primeiro lugar, não mais por meio da constituição política e seus guardiões, mas através dos potenciais comunicativos que se agrupam em torno dos diferentes meios de comunicação especializados da sociedade.

De um lado, é como se o poder político representativo (fundado na representação e no consenso) estivesse migrando das instituições políticas, para se manifestar em movimentos virtualizados, na multitudo que recepciona e orquestra em diferentes movimentos, como os protestos de ONGs, minorias, segmentos singulares de organismos que escapam à categorização tradicional da sociedade, encontrados dentro e fora das estruturas da democracia representativa. 
De outro, observa-se uma espécie de migração do poder constituinte derivado tradicional, de modo que o poder constituinte derivado passa a se identificar não mais o demos nacional, mas com processos jurisdicionais fragmentados (incidentais) ou concentrados.

Fica claro que não existe mais nenhuma dinâmica constitucional abrangente (vontade do povo), que abarque toda a sociedade nacional, mas que se trata de processos de constitucionalização extremamente heterogêneos, ora diretamente mediante decisões ostensivamente programantes, ora mediante um jogo de afirmação e contra afirmação, em que o Legislativo busca constitucionalizar o que foi declarado inconstitucional ou legalizar o que foi considerado ilegal, ora dispersando-se numa multiplicidade de agentes potenciais, energias e forças sociais.

Observa-se, então, o aparecimento de uma nova tendência democrática, que ganha sua força peculiar no acento depositado na noção de povo na expressão: soberania popular. Nela, o poder deixa de ser percebido exclusivamente como uma res do Estado, uma coisa que se tem, detém, transmite, e precisa ser limitado intensa e extensamente pela legislação (constitucional e infraconstitucional), para ser tomado como uma forma de relação social de dominação (no sentido weberiano de dominação), em que a soberania não mais é restrita a um poder de império enquanto um poder qualitativamente capaz de imposições contra as vontades particulares e, portanto, estatal (imperatividade estatal: proibições e obrigações), para tornar-se regulação, isto é, capacidade de fazer com que as vontades sejam conformadas antes de serem exercidas pela lei. O que, consequentemente, faz da imperatividade (poder de império) menos um poder centrípeto, mais um poder centrífugo.

Trata-se de um questionamento que atinge o Estado em suas principais configurações, seja o Estado percebido como fonte de organização política (fenômeno da descentralização das fontes), seja o Estado como esfera pública (fenômeno da diferenciação orgânica e a privatização da administração), seja o Estado como monopólio do império (fenômeno da redistribuição das prerrogativas de julgamento), seja o Estado-nação (fenômeno da internacionalização).

Por óbvio isso repercute intensamente no modo como se concebe hoje uma democracia e, nela, o papel desempenhado pelo Poder Judiciário.

O que se percebe, então, é que isso acaba por conduzir a um esgotamento da legitimação recíproca, quer do lado da legitimação política (vontade do povo), quer da legitimação jurídica (interpretação negativamente programante). Donde os efeitos desintegradores da [ultra]politização do direito e da [ultra]judicialização da política.

É inegável que se experimenta atualmente uma transformação no modo de encarar a Constituição, com um perceptível deslizamento do Poder Constituinte para o Poder Constituído.

Tudo isso acaba por se refletir nos julgamentos, cujas decisões parecem girar em torno delas mesmas. Ao invés de juízos fundados em uma base centrífuga de validade (topos da hierarquia, 
donde a primazia da Constituição, a Lei), parecem antes posicionamentos políticos, que se estabilizam por mútuas e ocasionais vinculações, donde essa sensação de desfalecimento da Constituição diante do poder para interpretá-la.

Vale dizer, a decisão jurídica ganha um destaque especial, pois se libera efetivamente de um todo pré-constituído. Em lugar do poder de decidir ela aparece como uma decisão de poder (não um decido porque posso, mas um posso porque decido), que está registrada numa ordem acêntrica e heterárquica, de possibilitar a abertura para o novo, para o desconhecido.

Mas, desse modo, a vinculação do privado ao público em termos de um Estado democrático - de Direito parece, então, sofrer uma espécie de erosão. Como se fossem subvertidos os conceitos (tradicionais) de consenso e representação, mediante uma explosão aparentemente incontrolável de manifestações desconectadas e sem um eixo perceptível.

Ou seja, dos poderes Executivo e Legislativo, tipicamente representativos, passa a exigirse, com forte intensidade, uma expressão de comunhão e nacionalidade, o que os põe em constante confronto por uma hegemonia legitimadora. Do poder Judiciário, classicamente, um poder não fundado na representação, mas no sentido solidário da comunhão nacional, passa a ser exigida alguma forma de representatividade, exigência dificilmente atendida e que acaba por abalar-lhe as bases.

Em consequência, a democracia parece, então, buscar sua legitimação não mais por meio da constituição política e seus guardiões, mas através dos potenciais meios comunicativos que se agrupam em torno dos novos e diferentes meios de comunicação da sociedade; vale dizer, pela colocação de subsetores sociais (mídia, redes sociais, blogs) no lugar da política mediante tripartição de poderes.

E esse, certamente, um desafio que se põe diante dos olhos de quem se dispõe a resgatar a democracia no mundo de hoje.

\section{REFERENCIAS:}

BOBBIO, Norberto Democrazia, maggioranza e minoranze, in Norberto Bobbio, Claus Offe, Siro Lombardini, Democrazia, maggioranza e minoranze, Bolonha: 1981

KELSEN. Hans. Vom Wesen und Wert der Demokratie, Berlim: Wentworth Press, 2018 [1920].

LUHMAN, Nicklas. Rechtssoziologie. Berlim: Okladen, 1983.

SIEYES, Emmanuel (Abbé). Qu'est-ce que le tiers état?. Livro digital, edição francesa. s/d [1789]. 